\title{
Erratum to: Visual Attention and Key Word Sign in Children with Autism Spectrum Disorder
}

\author{
Veronica Rose ${ }^{1,2,3}$. David Trembath ${ }^{1,2}$. \\ Karen Bloomberg ${ }^{3}$
}

Published online: 19 February 2016

(C) Springer Science+Business Media New York 2016

\section{Erratum to: J Dev Phys Disabil DOI 10.1007/s10882-015-9443-3}

The original published version of this article did not include sufficient information pertaining to ethical approval or a statement regarding disclosure of potential conflict of interest due to an error during the publication process. The authors have included this information below. This error has no implications for the analysis or reported results.

\section{Ethical Approval}

Ethical approval for this study was obtained from the La Trobe University Human Ethics Committee. All procedures were in accordance with the ethical standards of the institutional and/or national research committee and with the 1964 Helsinki declaration and its later amendments or comparable ethical standards.

\section{Conflict of Interest}

Veronica Rose and David Trembath report no potential conflict of interest. Karen Bloomberg was a training coordinator for Key Word Sign Australia at the time of the study. She did not receive financial remuneration for her services.

The online version of the original article can be found at http://dx.doi.org/10.1007/s10882-015-9443-3.

Veronica Rose

veronica.rose@griffithuni.edu.au

1 Olga Tennison Autism Research Centre, La Trobe University, Melbourne, Australia

2 Menzies Health Institute, Griffith University, Gold Coast, QLD 4222, Australia

3 Human Communication Sciences, La Trobe University, Melbourne, Australia 